\title{
Therapeutic Effects of Mechanical Horseback Riding on Gait and Balance Ability in Stroke Patients
}

\author{
Jun Young Han, M.D. ', Jong Moon Kim, M.D. ${ }^{1,3}$, Shin Kyoung Kim, M.D. ${ }^{1}$, Jin Sang Chung, M.D. ${ }^{1}$, \\ Hyun-Cheol Lee, M.D. ${ }^{1}$, Jae Kuk Lim, M.D. ${ }^{1}$, Jiwon Lee, M.D. ${ }^{1}$, Kawn Yong Park, R.P.T. ${ }^{2}$ \\ ${ }^{1}$ Department of Rehabilitation Medicine, School of Medicine, Konkuk University, ${ }^{2}$ Department of Physical Therapy, \\ Konkuk University Chungju Hospital, ${ }^{3}$ Korea Nokyong Research Center, Chungju 380-704, Korea
}

Objective To investigate the therapeutic effects of mechanical horseback riding for gait and balance parameters in post-stroke patients.

Method This study was a non randomized prospective positive-controlled trial over a 12 week period. From May 2011 to October 2011, 37 stroke patients were recruited from our outpatient clinic and divided into two groups. The control group received the conventional physiotherapy while the intervention group received the conventional physiotherapy along with mechanical horseback riding therapy for 12 weeks. Outcome measurements of gait included the Functional Ambulation Category (FAC) and gait part of the Performance Oriented Mobility Assessment (G-POMA) while those of balance included the Berg Balance Scale (BBS) and the balance part of the Performance Oriented Mobility Assessment (B-POMA). These measurements were taken before and after treatment.

Results There were no significant differences in the baseline characteristics and initial values between the two groups. When comparing baseline and 12 weeks post treatment in each group, the intervention group showed significant improvement on BBS $(39.9 \pm 5.7 \rightarrow 45.7 \pm 4.8, \mathrm{p}=0.001)$ and B-POMA $(10.4 \pm 2.6 \rightarrow 12.6 \pm 2.1, \mathrm{p}=0.001)$, but significant improvement on gait parameters. When comparing the groups, the dynamic balance category of BBS in post treatment showed significant difference $(\mathrm{p}=0.02)$.

Conclusion This study suggests that mechanical horseback riding therapy may be an effective treatment tool for enhancing balance in adults with stroke.

Key Words Hippotherapy, Stroke, Gait, Balance

Received May 2, 2012; Accepted August 9, 2012

Corresponding author: Jong Moon Kim

Department of Rehabilitation Medicine, Konkuk University Chungju Hospital, Gyohyeon 2-dong, Chungju 380-704, Korea

Tel: +82-43-840-8890, Fax: +82-43-851-3402, E-mail: rmjmk@kku.ac.kr

(ㄷ) This is an open-access article distributed under the terms of the Creative Commons Attribution Non-Commercial License (http:// creativecommons.org/licenses/by-nc/3.0) which permits unrestricted noncommercial use, distribution, and reproduction in any medium, provided the original work is properly cited.

Copyright $\odot 2012$ by Korean Academy of Rehabilitation Medicine

\section{INTRODUCTION}

Hippotherapy is a physical therapy treatment strategy using rhythmical equine movement that has been used since the 1960s in Europe and the mid 1970s in the USA for the treatment of cerebral palsy (CP). ${ }^{1,2}$ The horse is used as a facilitator and led by a horse master; a specially trained physical therapist walks beside the horse and is 
in close contact with the patient. ${ }^{3}$ The patient is passively influenced by equine movement. The horse provides a dynamic base of support, making it an excellent therapeutic tool for improving patients' trunk balance, control and strength. ${ }^{3}$ Hippotherapy acquires its distinct effect through a neural facilitation, vestibular stimulation, proprioceptive stimulation and psychosomatic influence. ${ }^{4}$ The main studies have been carried out on the basis that the horse's gait brings a rhythmic and repetitive pattern of movement, similar to the movements of human gait. ${ }^{5}$ Therefore, a patient with gait disturbance can be helped to acquire reciprocal aspects of movement and to improve posture control through the stimulation of normal balance reactions and posture coordination during the hippotherapy session. ${ }^{6,7}$

Several research studies have been published showing the beneficial effects of hippotherapy on patients with $\mathrm{CP}$ from gait speed and gross motor performance, ${ }^{8}$ decreased energy expenditure and increased efficiency while walking $^{9}$ and improvements in muscle symmetry. ${ }^{10}$ Also hippotherapy has been used as therapeutic intervention for a number of different neurologic conditions such as multiple sclerosis, ${ }^{11}$ spinal cord injury. ${ }^{3,12}$ Especially, Beinotti et al. reported that hippotherapy demonstrated a positive influence in gait training for hemiparetic poststroke. ${ }^{13}$ Hippotherapy associated with conventional physical therapy is a good resource in the treatment of hemiparetic patients after stroke. ${ }^{13}$ The study is clinically significant in that it evaluated the therapeutic effects of hippotherapy exclusively in stroke patients, but did not standardize physiotherapy between control and experimental group. Also, cost and risks of hippotherapy limits clinical applications.

The therapeutic results obtained with the application of hippotherapy treatments has encouraged research into developing an mechanical horseback riding therapy system that mimics the movements of a horse, so that this therapy may be more adaptable and accessible to patients. ${ }^{14}$ The development of mechanical horseback riding therapy system appears to be innovative. However, there are few studies about its therapeutic effects in patients with central nervous system lesions. In studies with $\mathrm{CP}$, the results showed that the use of horse riding simulator was superior to the conventional physical therapy both in the postural control and the sitting position. ${ }^{15,16}$ Lee et al. ${ }^{17}$ reported a positive response to mechanical horseback riding therapy in one patient with neuro- muscular scoliosis. Li et al. ${ }^{18}$ suggested that mechanical horseback riding could improve the balance in stroke patients as assessed with the Berg balance scale and the flat pressure test system. That study was limited to focusing only on balance ability.

We hypothesized that mechanical horseback riding therapy is a potential intervention with which to improve the balance and gait ability of patients with stroke. The purpose of this study is to evaluate the effect of mechanical horseback riding therapy on balance and gait after stroke.

\section{MATERIALS AND METHODS}

\section{Design}

This is a non randomized prospective positive-controlled trial over a 12 week period with pre and post measurements of gait and balance.

\section{Participants}

May 2011 to October 2011, nineteen volunteer patients with stroke were recruited from among outpatients into the intervention group (conventional physiotherapy plus mechanical horseback riding therapy). At the same time eighteen patients with stroke were recruited from among outpatients into the control group (conventional physiotherapy). This control group was selected from a larger

Table 1. Components of Berg Balance Scale (BBS) ${ }^{28}$

\begin{tabular}{llc}
\hline \multicolumn{1}{c}{ Category } & \multicolumn{1}{c}{ Component } & Score \\
\hline Sitting balance & Sitting unsupported & $0-4$ \\
Standing balance & Standing unsupported & $0-4$ \\
& Standing with eyes closed & $0-4$ \\
& Standing with feet together & $0-4$ \\
& Standing on one foot & $0-4$ \\
& Turning to look behind & $0-4$ \\
& Retrieving object from floor & $0-4$ \\
& Tandem standing & $0-4$ \\
& Reaching forward with an & $0-4$ \\
& $\quad$ outstretched arm & \\
Dynamic balance & Sitting to standing & $0-4$ \\
& Standing to sitting & $0-4$ \\
& Transfer & $0-4$ \\
& Turning 360 degrees & $0-4$ \\
Total & Stool stepping & $0-4$ \\
\hline
\end{tabular}


population who volunteered for the study and served as an age- and sex-matched group for comparison with the patients of intervention group.

Inclusion criteria included 1) prior diagnosis of single stroke confirmed by imaging study such as magnetic resonance imaging (MRI) or computed tomography (CT), 2) chronic phase more than 6 months after onset, 3) capability to sit upright unaided on a static surface (sitting balance category of Berg Balance Scale score $=4$ ) (Table 1), 4) sufficient cognition to follow verbal directions and understand the content and purpose of the study (Korean mini mental state examination score $\geq 24$ ), and 5) the ability to sit on mechanical horseback upright, unsupported, for 20 minutes.

Exclusion criteria were 1) bilateral stroke, 2) uncorrected visual impairments 3) co-morbidity that might interfere with mechanical horseback riding therapy such as psychiatric problems 4) aphasia with an inability to follow 2 consecutive step commands and 5) cognitive deficit with apraxia or neglect.

This study was approved by the Institutional Review Board at the Konkuk University Chungju Hospital (Approval No.: 2012-20). Informed consent was provided by patients before enrollment.

\section{Interventions}

The mechanical horseback riding therapy system utilized for this study is therapeutic apparatus called Joba ${ }^{\circledR}$ EU6441 (Panasonic Electric Works Co., Osaka, Japan) to reproduce the movement of the saddle during horseback riding..$^{19,20}$ One movement cycle of the Joba ${ }^{\circledR}$ apparatus is a set of back and forth swing/slide of the saddle, swaying left and right and returning to the initial position (Fig. 1). Movement speed of the Joba ${ }^{\circledR}$ equipment ranges from level $1(0.62 \mathrm{~Hz})$ to level $7(1.21 \mathrm{~Hz})$. There are three predefined tilt levels; basic conditioning (flat), forward tilt, backward tilt.

During the treatment sessions, patients maintain a sitting position on the simulator. The therapist helped the patients be safe by stabilization of patients' pelvis and holding the saddle.

Patients in the intervention group received 20 minutes of mechanical horseback riding therapy twice a week for 12 weeks added to conventional physiotherapy, while the control group received the same physiotherapy protocols only. The speed of machine was set at "level $3(0.82 \mathrm{~Hz})$ " and the tilt level was set at "basic conditioning". Conventional physiotherapy consisted of 30 minutes of neurodevelopmental therapy (NDT) twice a week for 12 weeks. All patients were treated by the same experienced physical therapist, certified in NDT.

\section{Outcome measure}

Clinical outcomes were blindly assessed by the same physician to reduce possible bias.

\section{Clinical evaluation of gait}

Functional Ambulation Category (FAC): The Func-

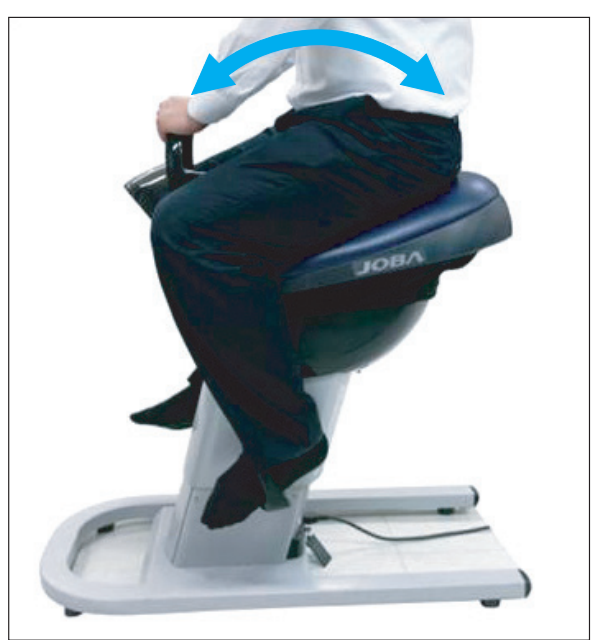

Swing front and rear

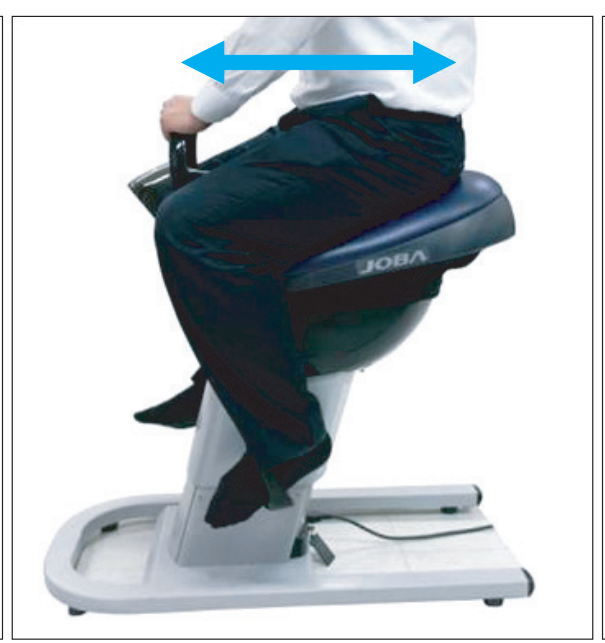

Slide front and rear

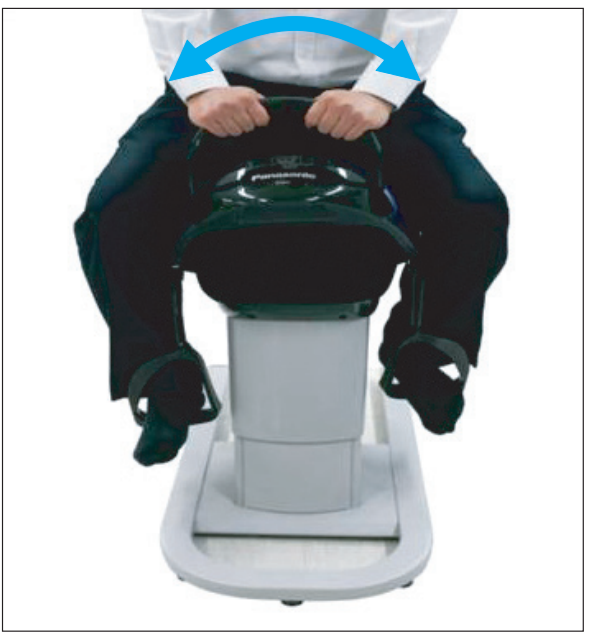

Swing right and left

Fig. 1. Movement pattern of hippotherapy simulator equipment. 
tional Ambulation Category (FAC) is a common clinical gait assessment scale first described by Holden et al. ${ }^{21}$ in 1984. The FAC differentiates 6 levels of walking ability on the basis of the amount of physical support required. The FAC was administered before and after intervention by the same examiner.

Gait part of Performance Oriented Mobility Assessment (G-POMA): Tinetti developed the Performance Oriented Mobility Assessment (POMA) in 1986. The POMA was originally designed as a measure for mobility and fall risk in elderly populations. High correlations between the gait subscale of POMA and physical performance test scores (Pearson $\mathrm{r}=0.78$ ). ${ }^{22}$ and between the balance subscale of POMA and the Berg Balance Scale $(r=0.91)^{23}$ have been reported, supporting the concurrent validity of the subscales. ${ }^{24}$ In the gait part of this test (G-POMA), eight characteristics of the walking pattern are scored on 2- or 3 -point scales for gait evaluation, resulting in a maximum score of 12. They are composed of gait initiation, step length, step height, step symmetry, step continuity, path deviation, trunk sway, walking stance and turning while walking. ${ }^{25}$

\section{Clinical evaluation of balance}

Berg Balance Scale (BBS): The Berg balance scale (BBS) is intended to measure a subject's ability to maintain balance while doing functional tasks. ${ }^{26}$ It is based on the principle that a person's balance is challenged by diminishing his/her base of support. ${ }^{27,28}$

The test includes fourteen items that are common in everyday life. These tasks progress from sitting to comfortable standing, to tandem standing, and to single leg standing. Each item of the BBS is rated on a 5-point scale.

Table 2. General Demographics of the Subjects

\begin{tabular}{|c|c|c|c|}
\hline & & $\begin{array}{l}\text { Control } \\
\text { group }\end{array}$ & $\begin{array}{l}\text { Intervention } \\
\text { group }\end{array}$ \\
\hline \multicolumn{2}{|c|}{ Number } & 18 & 19 \\
\hline \multicolumn{4}{|c|}{ Gender } \\
\hline \multicolumn{2}{|c|}{ Male } & 11 & 13 \\
\hline \multicolumn{2}{|c|}{ Female } & 7 & 6 \\
\hline \multicolumn{2}{|c|}{ Age (years) } & $62.2 \pm 6.9$ & $61.1 \pm 6.3$ \\
\hline \multicolumn{2}{|c|}{ Time since stroke (months) } & $12.4 \pm 3.7$ & $11.6 \pm 3.2$ \\
\hline \multirow[t]{2}{*}{ Type } & Hemorrhagic & 8 & 7 \\
\hline & Ischemic & 10 & 12 \\
\hline
\end{tabular}

Values are mean \pm standard deviation

The BBS assesses the static and dynamic balances by using usual tasks, such as reach, standing position, and transferences. ${ }^{29}$ In this study, we evaluated BBS in three categories - sitting balance, standing balance, dynamic balance (position change) (Table 1).

Balance Part of Performance Oriented Mobility Assessment (B-POMA): B-POMA is also from Tinetti's Performance Oriented Mobility Assessment. There are eight dynamic balance tasks scored on 2- or 3-point scales, resulting in a maximum score of 16 on the B-POMA. The tasks range from sitting and standing balance in a comfortable position to narrowing the base of support in standing. ${ }^{25}$

\section{Data analysis}

Descriptive statistics were used to summarize participant characteristics. Mann-Whitney U test and Chisquare test were used to confirm that initial gait and balance function, patient age, gender and duration of disease were similar between the control and intervention groups. Wilcoxon signed rank test was used to compare the effectiveness between baseline and 12 weeks after treatment in each group. Mann-Whitney $U$ test was used to compare between group effects. Statistic analyses were conducted using SPSS, Version 12.0 statistical soft-

Table 3. Comparisons of Gait and Balance Parameters before and after Treatment

\begin{tabular}{|c|c|c|c|c|}
\hline & \multicolumn{2}{|c|}{ Control group } & \multicolumn{2}{|c|}{ Intervention group } \\
\hline & $\begin{array}{c}\text { Pre } \\
\text { treatment }\end{array}$ & $\begin{array}{c}\text { Post } \\
\text { treatment }\end{array}$ & $\begin{array}{c}\text { Pre } \\
\text { treatment }\end{array}$ & $\begin{array}{c}\text { Post } \\
\text { treatment }\end{array}$ \\
\hline FAC & $3.2 \pm 0.6$ & $3.3 \pm 0.6$ & $3.1 \pm 0.9$ & $3.2 \pm 0.9$ \\
\hline G-POMA & $8.0 \pm 1.4$ & $8.2 \pm 1.3$ & $7.8 \pm 1.8$ & $7.8 \pm 1.5$ \\
\hline BBS & $42.7 \pm 3.9$ & $42.8 \pm 3.6$ & $39.9 \pm 5.7$ & $45.7 \pm 4.8^{*, \dagger}$ \\
\hline Sitting & $4.0 \pm 0.0$ & $4.0 \pm 0.0$ & $4.0 \pm 0.0$ & $4.0 \pm 0.0$ \\
\hline Standing & $25.4 \pm 2.3$ & $25.3 \pm 2.7$ & $24.1 \pm 3.8$ & $26.7 \pm 3.7^{*}$ \\
\hline Dynamic & $13.2 \pm 1.7$ & $13.5 \pm 1.3$ & $11.8 \pm 2.1$ & $15.1 \pm 1.7^{*, \dagger}$ \\
\hline B-POMA & $11.3 \pm 2.2$ & $11.4 \pm 1.9$ & $10.4 \pm 2.6$ & $12.6 \pm 2.1^{*}$ \\
\hline \multicolumn{5}{|c|}{$\begin{array}{l}\text { Values are mean } \pm \text { standard deviation } \\
\text { FAC: Functional ambulation category, G-POMA: Gait } \\
\text { part of performance oriented mobility assessment, BBS } \\
\text { Berg balance scale, B-POMA: Balance part of perfor- } \\
\text { mance oriented mobility assessment } \\
\text { *Statistically significant compared with pre-treatment } \\
\text { (p<0.05, Wilcoxon signed rank test), }{ }^{\dagger} \text { Statistically sig- } \\
\text { nificant difference between the groups ( } p<0.05 \text {, Mann- } \\
\text { Whitney U test) }\end{array}$} \\
\hline
\end{tabular}


ware SPSS V12.0K (SPSS Inc., Chicago, USA) and null hypotheses of no difference were rejected if $p$-values were less than 0.05 .

\section{RESULTS}

Nineteen patients were recruited to the intervention group and eighteen were in the control group. There were no differences in age, duration of disease and gender, nor were there any significant differences in parameters of clinical evaluation at baseline (Tables 2, 3).

There was no significant change in gait parameters after treatment for both intervention group and control group, and no difference between groups (Table 3 ).

Balance parameters improved significantly in the intervention group at 12 weeks after the treatment $(p=0.001$, Wilcoxon signed rank test). The dynamic balance category of BBS in post treatment especially was significantly different between groups ( $\mathrm{p}=0.02$, Mann-Whitney $U$ test) (Table 3). The B-POMA assessment improved significantly in the intervention group at 12 weeks after the treatment ( $p=0.001$, Wilcoxon signed rank test) but there was no significant difference between groups (Table 3 ).

\section{DISCUSSION}

Hippotherapy utilizes motor impulses generated from the back of a horse while the horse is walking. ${ }^{30}$ Locomotor impulses are the effects of the movement of the horse while walking and are transformed in the body of the rider. Locomotor impulses of the walking horse arise from the take-off of the rear limbs and impact of the front limbs. ${ }^{30}$ Locomotor impulses from the horse's back are transmitted to the rider at a frequency of 90 to $110 \mathrm{im}$ pulses a minute $(1.5-1.8 \mathrm{~Hz})$ in three movement planes. ${ }^{30}$ During a 30 minute hippotherapy session, patients experience approximately 2700 to 3300 repetitions of compulsory postural challenge. Heine ${ }^{31}$ reported that the movements of the horse generate continuous vestibular inputs that cause the practitioner to constantly adapt to these movements. Reactions to correct and re-balance are stimulated and this may lead to improve postural control and to aid the muscles of the trunk and extremities. ${ }^{13}$ In this way, hippotherapy is a multisensory motion in which the rhythmic and three-dimensional sway of horseback riding stimulates the patient's postural reflex mechanism, resulting in balance and coordination training. ${ }^{30}$
However there are several obstacles that complicate clinical application of hippotherapy like adverse weather conditions, difficulties to access to riding centers, the high costs, and the rejection of the therapy due to fear of the horse and the possibility of allergic reactions due to environmental antigens. More than all, horse riding is also associated with a high risk of serious injuries that can lead to long-term disabilities or death due to falling or kicks. ${ }^{32-35}$

For the purpose of preventing accidents and straightforwardly obtaining the physical benefits of horseback riding, a horseback riding simulator could replace the live horse. Mechanical horseback riding is more precisely reproducible and standardized for therapeutic purposes. ${ }^{19}$ The simulator has several advantages compared to real horseback riding. It can be used in any place, as an outpatient department or even in the patient's own home. It is independent of weather conditions and is small and quiet. It is easy to handle and it can be programmed for customized training. Above all things, it is comparatively safe from accidents.

The purpose of our investigation was to objectively evaluate the efficacy of mechanical horseback riding therapy in patients with stroke. We found that the BBS and B-POMA were significantly improved after the treatment. The balance category of BBS in post treatment differed significantly between groups. In mechanical horseback riding therapy, the riding simulator continuously and rhythmically imposes unconscious muscular reactions on the users to maintain upright posture..$^{19,20,36,37}$ and repeating a synchronized three-dimensional movement pattern promotes activating muscle in the dorsal and abdominal regions of the trunk, hip adductors to maintain posture against gravity. ${ }^{19,20,36,37}$ Therefore we assumed that repetition of these adjustments may cause mainly muscle strengthening of pelvic, abdominal and lumbar muscles, finally improving balance. Forced and dynamic movement of mechanical horseback in particular may affect dynamic balance more than static balance.

Hippotherapy and its therapeutic effects on the balance were reported earlier in relation to other clinical entities such as multiple sclerosis (MS). ${ }^{38,39}$ Silkwood-Sherer, et al. found significant improvements in BBS scores for the hippotherapy group in patients with MS. ${ }^{38}$ Hammer, et al. reported significant improvements in 3 out of 11 patients using the BBS and, when a qualitative measure was added to the analysis, balance improvements were reported 
in 8 patients with $\mathrm{MS} .^{39}$ Shurtleff et al. ${ }^{40}$ reported that hippotherapy improved dynamic stability as evaluated by a mechanical barrel to challenge trunk stability and functional reach test. Although patient groups vary, these results are similar to the findings of our study in terms of balance promotion.

Beinotti et al. ${ }^{13}$ examined the effects of hippotherapy for hemiparetic post-stroke, the only research about hippotherapy performed in patients with stroke. That was an experimental study with intervention and analyzed pre and post test in twenty subjects diagnosed with stroke. ${ }^{13}$ In that study, the patients were evaluated by using 1) the Functional Ambulation Category Scale, 2) Fugl-Meyer Scale, only the lower limbs and balance sub-items, 3) Berg Balance Scale, and 4) functional assessment of gait (cadence). The Fugl-Meyer assessment showed significant improvement in symptoms of motor impairment in the lower limbs in the experimental group. There was also a trend to improvement in the experimental group in Berg Balance Scale.

In short, our study has shown results similar to results of previous studies on the effectiveness of hippotherapy in terms of improving the balance. This demonstrates that mechanical horseback riding therapy may be a complementary treatment tool for enhancing balance in patients with stroke.

There are several limitations of our study. The major limitations include small sample size, lack of long-term follow-up and non randomization. Evaluation of additional outcome measures such as muscle strength, spasticity, sensory parameter, gait analysis and activities of daily living may be included in the future trial design. Despite the several limitations mentioned above, our study showed the possibility of mechanical horseback riding therapy as a complementary treatment.

\section{CONCLUSION}

The effectiveness of hippotherapy has already been demonstrated, but in many cases it is not possible to put it into practice due to various reasons such as financial considerations, difficulty of mounting a horse, and high risk of serious injuries. This study is one of the first to assess the effect of hippotherapy simulators therapy on stroke patients. We showed the beneficial effect of hippotherapy simulator on balance improvement in patients with stroke.

\section{REFERENCES}

1. Herrero P, Asensio A, Garcia E, Marco A, Olivan B, Ibarz A, Gomez-Trullen EM, Casas R. Study of the therapeutic effects of an advanced hippotherapy simulator in children with cerebral palsy: a randomised controlled trial. BMC Musculoskelet Disord 2010; 11: 71

2. Snider L, Korner-Bitensky N, Kammann C, Warner $\mathrm{S}$, Saleh M. Horseback riding as therapy for children with cerebral palsy: is there evidence of its effectiveness? Phys Occup Ther Pediatr 2007; 27: 5-23

3. Lechner HE, Kakebeeke TH, Hegemann D, Baumberger $M$. The effect of hippotherapy on spasticity and on mental well-being of persons with spinal cord injury. Arch Phys Med Rehabil 2007; 88: 1241-1248

4. McGibbon NH, Benda W, Duncan BR, SilkwoodSherer D. Immediate and long-term effects of hippotherapy on symmetry of adductor muscle activity and functional ability in children with spastic cerebral palsy. Arch Phys Med Rehabil 2009; 90: 966-974

5. MacPhail H, Edwards J, Golding J, Miller K, Mosier C, Zwiers T. Trunk postural reactions in children with and without cerebral palsy during therapeutic horseback riding. Pediatric Physical Therapy 1998; 10: 143147

6. Bertoti DB. Effect of therapeutic horseback riding on posture in children with cerebral palsy. Phys Ther 1988; 68: 1505-1512

7. Shinomiya Y, Ozawa T, Hosaka Y, Wang S, Ishida K, Kimura T. Development and physical training evaluation of horseback riding therapeutic equipment. Advanced Intelligent Mechatronics, 2003. AIM 2003. Proceedings. 2003 IEEE/ASME International Conference on; 2003 July 20-24; Kobe, Japan. New Jersey: Institute of Electrical and Electronics Engineers, 2003

8. Winchester P, Kendall K, Peters H, Sears N, Winkley $\mathrm{T}$. The effect of therapeutic horseback riding on gross motor function and gait speed in children who are developmentally delayed. Phys Occup Ther Pediatr 2002; 22: 37-50

9. McGibbon NH, Andrade CK, Widener G, Cintas HL. Effect of an equine-movement therapy program on gait, energy expenditure, and motor function in children with spastic cerebral palsy: a pilot study. Dev Med Child Neurol 1998; 40: 754-762

10. Benda W, McGibbon NH, Grant KL. Improvements 
in muscle symmetry in children with cerebral palsy after equine-assisted therapy (hippotherapy). J Altern Complement Med 2003; 9: 817-825

11. Bronson C, Brewerton K, Ong J, Palanca C, Sullivan SJ. Does hippotherapy improve balance in persons with multiple sclerosis: a systematic review. Eur J Phys Rehabil Med 2010; 46: 347-353

12. Lechner HE, Feldhaus S, Gudmundsen L, Hegemann D, Michel D, Zach GA, Knecht H. The short-term effect of hippotherapy on spasticity in patients with spinal cord injury. Spinal Cord 2003; 41: 502-505

13. Beinotti F, Correia N, Christofoletti G, Borges G. Use of hippotherapy in gait training for hemiparetic poststroke. Arq Neuropsiquiatr 2010; 68: 908-913

14. Kijima R, Kouno M, Hashimoto K, Jiang Y, Aoki T, Ojika T. Karakuri Horse Riding Therapy. Proc of the 8th International Conference on Rehabilitation Robotics; 2003 April 23-25; Daejeon, Korea. Seoul: Korean Institute of Intelligent Systems, 2003

15. Silva e Borges MB, Werneck MJ, da Silva Mde L, Gandolfi L, Pratesi R. Therapeutic effects of a horse riding simulator in children with cerebral palsy. Arq Neuropsiquiatr 2011; 69: 799-804

16. Herrero P, Gomez-Trullen EM, Asensio A, Garcia E, Casas R, Monserrat E, Pandyan A. Study of the therapeutic effects of a hippotherapy simulator in children with cerebral palsy: a stratified single-blind randomized controlled trial. Clin Rehabil 2012; 26: 1105-1113

17. Lee DR, Lee NG, Cha HJ, O YS, You SJ, Oh JH, Bang HS. The effect of robo-horseback riding therapy on spinal alignment and associated muscle size in MRI for a child with neuromuscular scoliosis: an experimenterblind study. NeuroRehabilitation 2011; 29: 23-27

18. Li X, Sang D, Piao C. Effects of mechanical horseback riding on balance ability in stroke patients. Chinese Journal of Rehabilitation Theory and Practice 2009; 11: 1051-1053

19. Shinomiya Y, Sekine O, Yamamoto T, Hojo H, Ono T, Kamizono Y. Development of horseback riding therapeutic equipment and verification of effect on increase in muscle strength. MEW Technical Report 2001; 76: 69-74

20. Shinomiya Y, Wang S, Ishida K, Kimura T. Development and muscle strength training evaluation for horseback riding therapeutic equipment. Journal of Robotics and Mechatronics 2002; 14: 597-603

21. Holden MK, Gill KM, Magliozzi MR, Nathan J, Piehl-
Baker L. Clinical gait assessment in the neurologically impaired. Phys Ther 1984; 64: 35-40

22. Reuben DB, Siu AL. An objective measure of physical function of elderly outpatients. The Physical Performance Test. J Am Geriatr Soc 1990; 38: 1105-1112

23. Berg KO, Maki BE, Williams JI, Holliday PJ, WoodDauphinee SL. Clinical and laboratory measures of postural balance in an elderly population. Arch Phys Med Rehabil 1992; 73: 1073-1080

24. Faber MJ, Bosscher RJ, Chin A Paw MJ, van Wieringen PC. Effects of exercise programs on falls and mobility in frail and pre-frail older adults: a multicenter randomized controlled trial. Arch Phys Med Rehabil 2006; 87: 885-896

25. Tinetti ME. Performance-oriented assessment of mobility problems in elderly patients. J Am Geriatr Soc 1986; 34: 119-126

26. Berg KO, Wood-Dauphinee SL, Williams JI, Gayton D. Measuring balance in the elderly: preliminary development of an instrument. Physiotherapy Canada 1989; 41: 304-311

27. Berg KO, Maki BE, Williams JI, Holliday PJ, WoodDauphinee SL. Clinical and laboratory measures of postural balance in an elderly population. Arch Phys Med Rehabil 1992; 73: 1073-1080

28. Berg KO, Wood-Dauphinee SL, Williams JI, Maki B. Measuring balance in the elderly: validation of an instrument. Can J Public Health 1992; 83 Suppl 2: S7-11

29. Aydog E, Depedibi R, Bal A, Ekşioglu E, Unlü E, Cakci A. Dynamic postural balance in ankylosing spondylitis patients. Rheumatology 2006; 45: 445-448

30. Janura M, Peham C, Dvorakova T, Elfmark M. An assessment of the pressure distribution exerted by a rider on the back of a horse during hippotherapy. Hum Mov Sci 2009; 28: 387-393

31. Heine B. Hippotherapy. A multisystem approach to the treatment of neuromuscular disorders. Aust J Physiother 1997; 43: 145-149

32. Ball CG, Ball JE, Kirkpatrick AW, Mulloy RH. Equestrian injuries: incidence, injury patterns, and risk factors for 10 years of major traumatic injuries. Am J Surg 2007; 193: 636-640

33. Kiuru MJ, Koivikko MP, Koskinen SK. Serious horseriding accidents: imaging findings and evaluation with multi-slice CT. Emerg Radiol 2002; 9: 213-218

34. Siebenga J, Segers MJ, Elzinga MJ, Bakker FC, Haarman HJ, Patka P. Spine fractures caused by horse rid- 
ing. Eur Spine J 2006; 15: 465-471

35. Thomas KE, Annest JL, Gilchrist J, Bixby-Hammett DM. Non-fatal horse related injuries treated in emergency departments in the United States, 2001-2003. Br J Sports Med 2006; 40: 619-626

36. Kitagawa T, Takeuchi T, Shinomiya Y, Ishida K, Wang S, Kimura T. Cause of active motor function by passive movement. Journal of Physical Therapy Science 2001; 13: $167-172$

37. Nakajima R, Shinomiya Y, Sekine O, Wang S, Ishida $\mathrm{K}$, Kimura T. Horseback riding therapy system using VR technology, and toward to its medical evaluation. Trans Hum Interface Soc 1999; 1: 81-86

38. Silkwood-Sherer D, Warmbier H. Effects of hippo- therapy on postural stability, in persons with multiple sclerosis: a pilot study. J Neurol Phys Ther 2007; 31: 77-84

39. Hammer A, Nilsagard Y, Forsberg A, Pepa H, Skargren E, Oberg B. Evaluation of therapeutic riding (Sweden)/ hippotherapy (United States). A single-subject experimental design study replicated in eleven patients with multiple sclerosis. Physiother Theory Pract 2005; 21: 51-77

40. Shurtleff TL, Standeven JW, Engsberg JR. Changes in dynamic trunk/head stability and functional reach after hippotherapy. Arch Phys Med Rehabil 2009; 90: 1185-1195 